\title{
Aerosol Profiling Using a Tethered Balloon in Coastal Antarctica
}

\author{
ANDREW M. RANKIN AND ERIC W. WOLFF \\ British Antarctic Survey, Natural Environment Research Council, Cambridge, United Kingdom
}

(Manuscript received 19 December 2001, in final form 14 June 2002)

\begin{abstract}
The composition of air near ground level is not necessarily representative of the troposphere as a whole. In particular in the Antarctic, stratification from the strong inversions often present and scavenging by blowing snow in the lowest part of the boundary layer may lead to air masses aloft being of different composition than those at ground level. The difference in aerosol composition with height in the Antarctic has been shown for the first time with a lightweight sampling system capable of being hoisted to heights of a few hundred meters on a helium-filled blimp. The system was tested at Halley research station in the Weddell Sea region of coastal Antarctica. On more than one occasion, air with a strong sea-salt aerosol component was found aloft, despite the air at ground level showing little marine influence. Meteorological instruments carried on the blimp just prior to one such flight indicated the presence of a strong inversion at the time.
\end{abstract}

\section{Introduction}

Aerosol sampling is most frequently carried out within a few meters of ground level for logistical reasons. However, air that is sampled near the ground is not necessarily representative of the whole air column. In a stratified atmosphere, the various air masses present will have different histories-they will not have been exposed to the same sources of aerosol or meteorological conditions - and thus are likely to be chemically distinct. Only in a well-mixed column might homogeneity in the aerosol composition be expected, but, when sampling is very near the ground, local sources and sinks may still influence the aerosol present.

In the Antarctic, there is also the particular problem of blowing snow near ground level. Blowing snow can reach heights of a few meters above the surface (Mellor and Radok 1960) - higher than many air sampling inlets-and is likely to "clean" the air by scavenging the aerosol from it (Pomeroy and Jones 1996). Yet obtaining a representative picture of the aerosol composition of the atmosphere is particularly important in the Antarctic. Falling snow will collect aerosol from the whole air column from the cloud level downward, and this material will ultimately become incorporated in the ice of the Antarctic ice sheet. Ice cores retrieved from ice sheets can tell us about the past history of aerosol in the Antarctic atmosphere (Wolff 1996), but to relate such analyses to climatic parameters it is necessary to

Corresponding author address: Andrew M. Rankin, Physical Sciences Division, British Antarctic Survey, High Cross, Madingley Rd., Cambridge, CB3 OET, United Kingdom.

E-mail: a.rankin@bas.ac.uk understand the sources of the aerosol to the atmosphere, the transport pathways that bring it to the Antarctic, and any processes that may modify its composition. There is therefore considerable interest in understanding aerosol dynamics in the Antarctic in the present day, and sampling campaigns at ground level have been undertaken at a number of research stations in Antarctica, such as McMurdo (Mazzera et al. 2001), the South Pole (Hogan and Gow 1993), Neumayer, Dumont d'Urville, and Halley (Wolff et al. 1998b).

One study (Wolff et al. 1998a) has looked at the correlation of concentrations between ions in surface snow samples and aerosol collected at Halley. Although similar seasonal patterns were found in aerosol and snow, a poor relationship was found for individual snowfalls; a possible explanation given was that the aerosol samples (which were collected at an inlet less than $2 \mathrm{~m}$ above the ground) might not be representative of concentrations at higher altitudes. A study of the relationship between aerosol measurements and records retrieved from firn cores at the South Pole attributed differences to a lack of understanding of the processes that mix surface air with air aloft (Bergin et al. 1998). Another study at the South Pole (Harder et al. 2000) suggested that the strong surface-based temperature inversion present in winter inhibits vertical motion and may limit the rate of delivery of aerosol to the boundary layer from the free troposphere. Because the snow surface is a sink for aerosol, near-surface measurements of aerosol in the stable inversion layer may not be representative of the free troposphere and, therefore, may not be relevant for understanding the air-snow relationship and transfer functions. 
Clearly, it is beneficial to collect aerosol from greater heights in the troposphere as well as at ground level to ensure that any differences between the ground and aloft may be accounted for. One way that aerosol aloft has been studied is with research aircraft equipped with aerodynamic inlets to allow collection of aerosol while flying. This technique has been used in a large number of studies in regions as diverse as the North Sea (Rojas et al. 1993), the Amazon basin (Artaxo et al. 1998, 2000), northern India (Paul 2000), and the Arctic (Sheridan et al. 1993), to name but a few examples.

However, aircraft campaigns are expensive and logistically complex and can in any case give only a snapshot of the aerosol at a particular point as the plane passes through. If aerosol filters are required for chemical measurements, then aircraft can only provide an average measurement for a large and potentially inhomogeneous region of the atmosphere. An alternative and far less expensive method of placing a sampling instrument aloft is to use a kite or a tethered helium balloon. Instruments on tethered balloons have in the past been used for a number of chemical and meteorological studies, measuring such species as carbon dioxide (Kuck et al. 2000), volatile organic carbons (Greenberg et al. 1999), nonmethane hydrocarbons (Helmig et al. 1998), ozone (Sanhueza et al. 2000), and nitrogen dioxide (Pisano et al. 1996) in addition to a number of meteorological parameters (e.g., Argentini et al. 1999). Kites have been used in conjunction with tethered balloons to extend the range of wind conditions in which sampling may be undertaken (Eaton et al. 2000; Knapp et al. 1998). To our knowledge, helium blimps or kites have not previously been used to carry pumps and filters for aerosol collection onto filters for subsequent chemical analysis.

In this paper a small, lightweight air sampling unit for use on a helium blimp is described. The unit was designed and built at the British Antarctic Survey and was deployed at Halley research station in January and February of 2000 to heights of a few hundred meters above the snow surface. Preliminary results from this first sampling campaign are presented.

\section{Development of equipment}

\section{a. Platform}

A helium blimp was chosen as the means of lifting the air-sampling pump because it permitted deployment at the low wind speeds that are most frequently encountered at Halley during the summer months. However, there is no reason that the same pump could not be used in future campaigns with a suitably large kite to extend the range of wind speeds in which sampling could be undertaken.

A $400-\mathrm{ft}^{3}$ blimp, supplied by Cameron Balloons, Ltd., had a standard design but used a lighter-weight fabric than normal to increase the lifting capacity of the blimp.
The fabric was tested in a cold room at $-20^{\circ} \mathrm{C}$ before the blimp was constructed to ensure that it was suitable for use in the cold temperatures experienced in the Antarctic. Spectra line, $3 \mathrm{~mm}$ in diameter, was used as the tether because it has a good strength-to-weight ratio.

Initially a hand-operated drum was used to wind the blimp up and down. However, it was found that in any wind the tension on the line made this difficult to use, and a small electrically powered winch was used instead. This winch was mounted on a sledge and was powered by a variable-speed 1000-W motor running through a gearbox that gave raising and lowering speeds of a little over $1 \mathrm{~m} \mathrm{~s}^{-1}$.

\section{b. Instrumental design and development}

A maximum weight of around $3 \mathrm{~kg}$ was aimed for when building the air-sampling unit. The free lift of the blimp was approximately double this, but only one-half the available lift was used-partly to account for the weight of the tether itself but also partly to keep some tension on the line, since with little tension the blimp blows sideways and does not reach a great height. Although some additional lift is gained in wind from the aerodynamic shape of the blimp, drag on the tether also increases, and so this factor does not permit any increase in payload size.

An aerosol sampling system requires a number of elements. A filter is necessary to collect the aerosol, and a pump is used to draw air through the filter. Because it is important to know the volume of air passed through the filter, a flow- or volume meter must be included. A power source is needed for the pump.

\section{c. Filters}

The filters chosen were Gelman 37-mm-diameter Zefluor Teflon filters, because these had been tried and tested in an aerosol monitoring system previously used at Halley (Wagenbach et al. 1998) and could be brought down to the Antarctic having already been inserted into acrylic filter monitors. Handling steps could thus be minimized in the field. Blanks were known to be low for this type of filter-typically only a few nanograms per filter for sodium and chloride (Hall 1998). An added advantage was the light weight of the filter monitors available for $37-\mathrm{mm}$ filters.

Filter monitors were attached to the inlet of the flowmeter by push-fit onto a Luer adaptor screwed onto the $1 / 4$-in. National Pipe Thread (NPT) flowmeter inlet. With suitable fittings it would be easy to adapt the instrument to take other types of filter-the unit was also tested with a $1 / 4-i n$. NPT female fitting attached to a 47-mm Nuclepore "Swin-lok" filter monitor, although only the Gelman 37-mm filters and monitors were used in this study. 


\section{d. Flowmeter and logger}

A Honeywell 5103VN mass flow transducer was used to measure the flow rate through the filter. The transducer is small and weighs only $66 \mathrm{~g}$. It requires an input voltage of between 8 and $15 \mathrm{~V}$ dc. Initially, 10.8-V lithium-ion batteries were used to power both the pump and the flowmeter. However, since the flowmeter output voltage is proportional to the input voltage, this configuration was found to be unsatisfactory, because the voltage from the batteries dropped during a flight, affecting the accuracy of the flows measured. A separate 9-V PP3 battery was instead used to power the transducer. At the beginning and end of every flight, this battery voltage was recorded in the datalogger. Changes in the voltage during the flight were found to be small because of the low power consumption of the transducer, and flow rates were corrected for the small variations that did exist by assuming any drift in the battery voltage to be linear with time.

The dataloggers employed to log the voltage output from the flow sensors were Gemini Tinytalk II miniature voltage loggers. These miniature units are contained in a film canister cartridge and can be set to log voltages in ranges of $0-2.5,0-10$, or $0-25 \mathrm{~V}$ dc. The $0-10-\mathrm{V}$ range was used in this instance. The loggers are programmed via a personal-computer interface to take up to 1800 readings at a time interval specified by the user. Typically, the readings were taken every $20 \mathrm{~s}$, allowing for a maximum flight duration of $10 \mathrm{~h}$. After downloading, the measured voltages were converted to flow rates and were integrated to give the total volume passed through the filter.

\section{e. Pump}

A rotary-vane air pump was chosen because it gives the highest flow rate for a given weight of unit. A Fürgut DC12/9052 double-headed pump was used initially and gave a flow rate of approximately $18 \mathrm{~L} \mathrm{~min}^{-1}$ with the two heads plumbed in parallel. However, an ASF Thomas G/07-N pump was later substituted because it was considerably lighter (395 g) than the Fürgut pumps, although it gave a slightly lower flow rate (around $14 \mathrm{~L}$ $\min ^{-1}$ when pumping through a Teflon filter).

\section{f. Power source}

A conducting tether was one possibility for powering the pump on the blimp. Although this would have meant no limit to the length of time pumping could be undertaken, such a system has significant drawbacks. For a pump system running at $12 \mathrm{~V}$, the diameter of the cables in the tether would have to be large to avoid voltage drops along the long length of tether needed, and the weight of the tether would soon become an issue and prevent deployment to a reasonable height. The thicker cable would also increase wind drag. Although
TABLE 1. Weights of components of the sampling system.

\begin{tabular}{lc}
\hline \hline Component & Weight $(\mathrm{g})$ \\
\hline Filter monitor & 12 \\
Pump & 395 \\
Flowmeter & 66 \\
PP3 battery & 45 \\
Lithium ion batteries & $4 \times 439$ \\
Total & 2274 \\
\hline
\end{tabular}

high voltages could be passed along the tether and a transformer or solid state dc-dc converter could be used to step down the voltage on the blimp, allowing thinner wires, the weight of the transformer or converter would to some extent negate the advantages of being able to use thinner wire for the tether, and the use of high voltages would also have discouraging safety implications.

Batteries were therefore used to power the pumping unit. The rotary-vane pump used was rated at $73 \mathrm{~W}$ when running at $12 \mathrm{~V} \mathrm{dc}$, and, to pump sufficient air through the filter to collect enough aerosol to be above detection limits, we needed to pump at least $2 \mathrm{~m}^{3}$ of air, or a little over $2 \mathrm{~h}$ of pumping at $14 \mathrm{~L} \mathrm{~min}^{-1}$. Around $200 \mathrm{~W}$ h of energy in the batteries was therefore felt to be a reasonable minimum.

With approximately $2 \mathrm{~kg}$ of payload available for the batteries, this meant the energy density of the batteries had to be around $100 \mathrm{~W} \mathrm{~h} \mathrm{kg-1}$. Lead-acid, nickelcadmium, and nickel-metal hydride technologies do not reach this energy density (Beck and Ruetschi 2000), so Energizer NI2020 lithium-ion battery packs were used. These weighed $439 \mathrm{~g}$ each, and stored $4.5 \mathrm{~A} \mathrm{~h}$ at 10.8 V. Normally four were used to power the pump, wired in parallel. Lithium-ion batteries do not lose much capacity at low temperatures - an important advantage in the Antarctic.

The total weight of the instrument with four lithiumion batteries was $2274 \mathrm{~g}$. Table 1 gives a breakdown of the weights of the individual components. Figure 1 is a schematic of the components used in the pumping system, and Fig. 2 shows a view of the pumping system suspended beneath the belly of the blimp.

The efficiency of an aerosol collection system can be affected by the airflow around the intake, since large particles in particular may not be able to follow sharp changes in airflow direction because of their high momentum (Vincent 1989). The presence of the blimp close to the sampler sent aloft is one factor that may affect airflow patterns around the unit. No attempt has been made to correct observed aerosol loadings for such effects, because they will also vary with the prevailing wind speed, the orientation of the intake into the wind, and the size distribution of the aerosol. They should, however, be small in the low wind speeds in which the experiments were undertaken.

\section{g. Meteorological sonde}

On one flight, a lightweight meteorological sonde was hoisted with the blimp to give a profile of the prevailing 


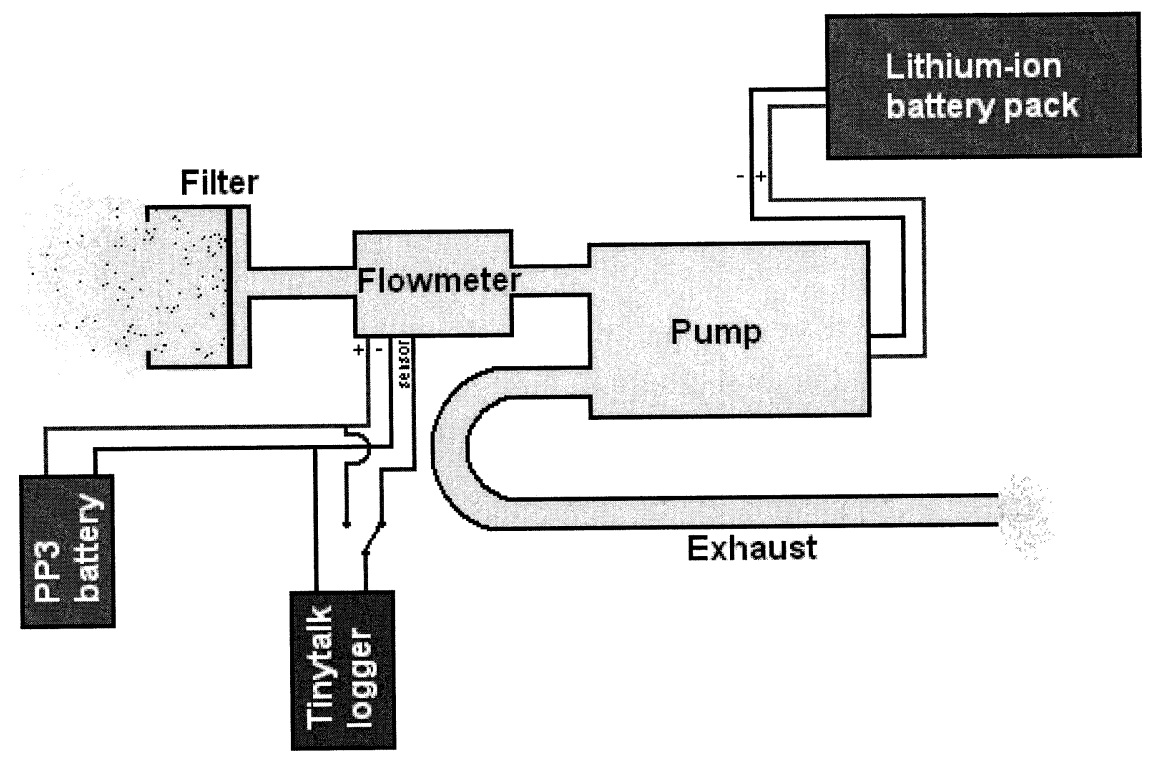

FIG. 1. Schematic of components of the sampling system.

meteorological conditions. The RuSonde was developed at the British Antarctic Survey and includes a Vaisala PTB 100 pressure sensor, a small platinum resistance thermometer element, a cup anemometer, and a Pewatron Model 6100 compass with Hall effect sensors to give wind direction. Data are telemetered back by a VHF radio link to a laptop computer on the ground.

\section{Sampling site}

The British Antarctic Survey Halley research station is situated at $75^{\circ} 35^{\prime} \mathrm{S}, 26^{\circ} 19^{\prime} \mathrm{W}$ on the Brunt Ice Shelf, to the east of the Weddell Sea in the Atlantic sector of Antarctica. The station is approximately $15 \mathrm{~km}$ from the coast and $40 \mathrm{~km}$ from the grounding line where the ice begins to rise steeply to the Coats Land plateau (Fig. 3).

The nearest wildlife to Halley is a penguin colony 15 $\mathrm{km}$ to the north, which is not thought to significantly affect aerosol collected at the station (Rankin and Wolff 2000). The nearest rock outcrop is over $200 \mathrm{~km}$ away. Aerosol at Halley is therefore dominated by marine sources - sea salt from open water in summer and frost flowers on the surface of newly forming sea ice in winter (Wagenbach et al. 1998; Rankin et al. 2000) and sulfate and methane sulfonic acid derived from marine biogenic activity (Minikin et al. 1998).

Halley lies south of the main cyclonic midlatitude belt, but a significant number of cyclones do track far enough south to affect the weather there. The prevailing wind owing to to the synoptic pressure gradient is, however, easterly (König-Langlo et al. 1998). Inversions are common at Halley, particularly in the winter months. Because of the stability of the lower atmosphere, surface winds can be decoupled from winds aloft_-indeed, anal- ysis of wind profiles from sounding balloons at Halley has shown that it is not uncommon for winds at 2000 $\mathrm{m}$ to be blowing in the direction opposite to that of the surface wind (King 1989). With such winds, blowing from different source areas, one might expect a considerable variation in aerosol composition with height.

\section{Experimental methods \\ a. Field work}

Aerosol sampling experiments with the blimp were carried out at Halley during January and early February of 2000. The number of flights was restricted by the availability of suitable weather windows (the blimp manufacturer recommends a maximum wind speed of $12 \mathrm{~m} \mathrm{~s}^{-1}$, although in practice it was not flown in ground-level winds of greater than $8 \mathrm{~m} \mathrm{~s}^{-1}$ ) and by aircraft activity at the base. A total of 12 flights were carried out. Data are presented for only nine of them, because problems were experienced with the flow-rate loggers or power connections on three flights.

In addition to the pumping unit deployed on the blimp, a second pumping unit was positioned $0.1 \mathrm{~m}$ above the snow surface during each flight, so that the aerosol aloft could be compared with that near ground level. This used the same pump, flowmeter, and logger as the airborne unit, but the pump was powered by a large $12-\mathrm{V}$ lead-acid battery, since there was no requirement for this unit to be lightweight. During the final flight (No. 9), six pumps were set up simultaneously at ground level to verify that sampling of the same air mass gave consistent results. Three of these pumps were of the same design as the pump on the blimp; the remainder were diaphragm pumps of a similar flow rate. 


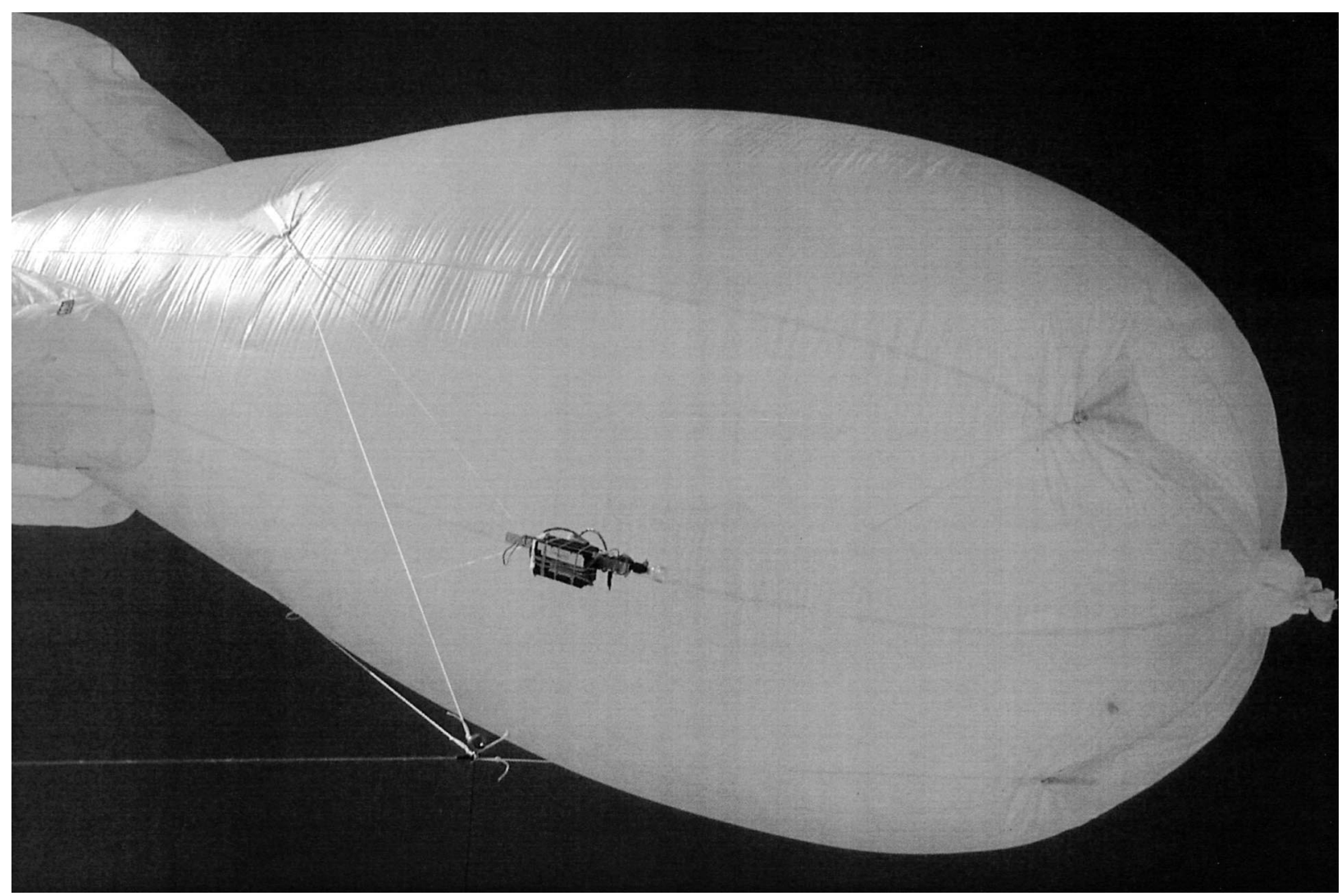

FIG. 2. The sampling system suspended beneath the belly of the blimp. The blimp is approximately $7 \mathrm{~m}$ long.

The duration of each flight was normally determined by the capacity of the batteries powering the sampling unit on the blimp. It was found that one battery would power the pump for approximately $1 \mathrm{~h}$-slightly more than was expected from the rated current of the pump. Although at least six batteries could be carried by the blimp, with a small amount of positive buoyancy remaining, four were normally used so as to keep a reasonable tension on the tether. Because there was no remote control of the pump on the blimp, it was started just before the ascent began. Thus, for a short period of time each flight, the pump would be sampling air near ground level-but, because this would only be for a few minutes at most in a 4-h flight it is not expected to affect the results to a great extent. Once the unit on the blimp was deployed, the pump near ground level was switched on.

After $4 \mathrm{~h}$ the pump near ground level was switched off, and the blimp was brought back to the surface. The filter monitors were removed from the pumps, were sealed in double plastic bags, and were transported at $-20^{\circ} \mathrm{C}$ to the United Kingdom for analysis.

Surface winds near the midpoint of each flight (taken from hourly meteorological records maintained at Halley) are included in Table 2. Because the blimp was not flown in high wind speeds, blowing snow was never present at ground level during any of the runs, and so scavenging by blowing snow is not likely to have reduced the aerosol loading.

\section{b. Extraction and analysis}

Filters were removed from the filter monitors in a clean room and were placed in sample containers. A known amount of ultra high purity water was added, and the sample containers were agitated for $15 \mathrm{~min}$ to dissolve the soluble aerosol collected on the filters.

Small quantities of the extract were then analyzed on Dionex DX 500 ion chromatographs. Anions were analyzed using a 500- $\mu \mathrm{L}$ sample loop injection and gradient elution with potassium hydroxide eluent, and cations were analyzed with a 500- $\mu \mathrm{L}$ sample loop injection and isocratic methane sulfonic acid eluent.

Uncertainties in ion chromatography measurements are typically around 5\% (higher near the detection limit). Because the output voltage from the sensors used to measure flow rate (and hence volume pumped) was proportional to the input voltage, variations in the battery voltage during a flight are also a source of error in the aerosol loadings calculated. It was common for the battery voltage to drop as much as $10 \%$ during a flight, and although it was assumed that the drop was linear with time this is unlikely to be the case.

The standard deviations of the sodium and chloride 


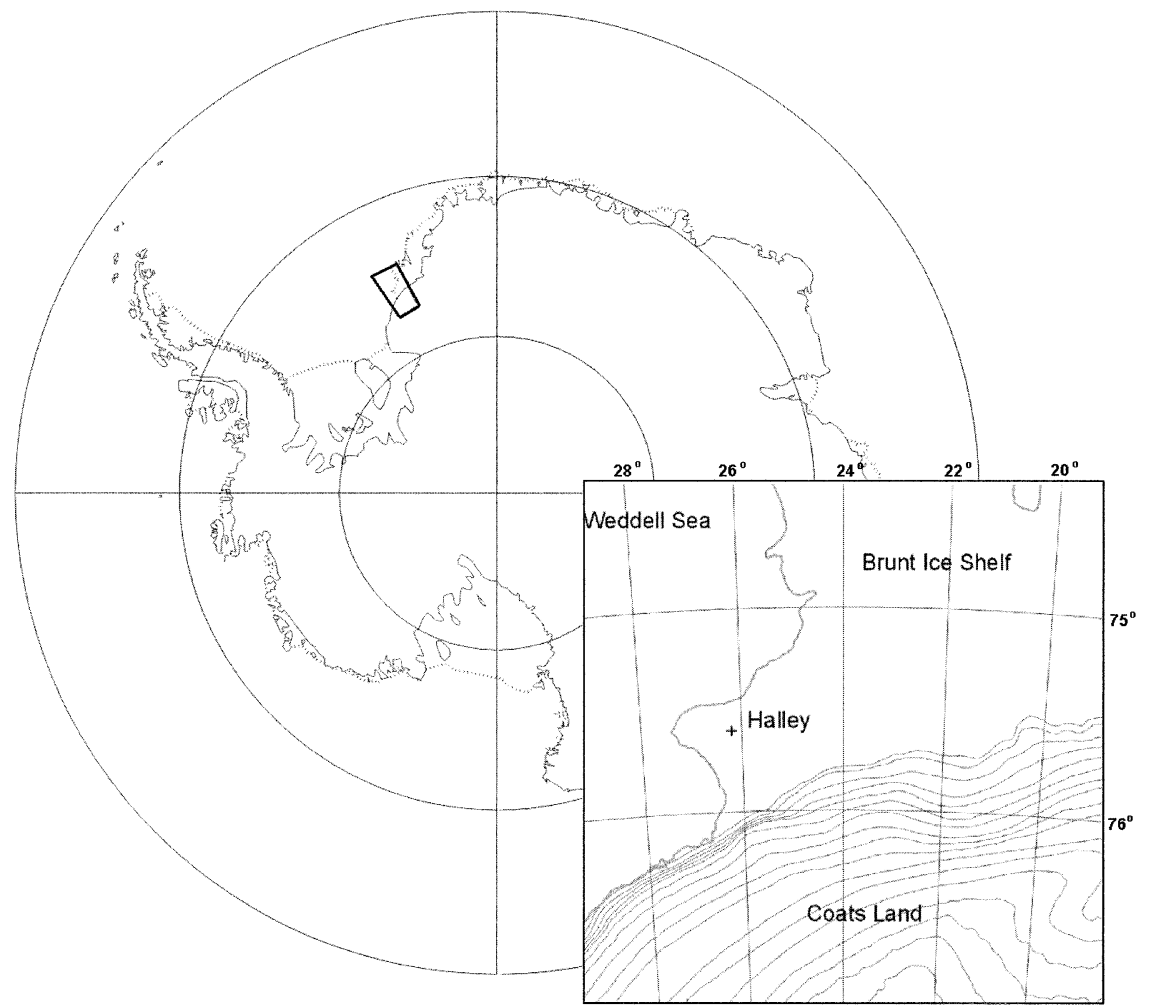

FIG. 3. Map of the Antarctic with inset of the Brunt Ice Shelf, showing the location of Halley Base, where the experiments were undertaken.

concentrations in the six samples taken simultaneously at ground level during flight 9 (Table 2) are another indication of the uncertainty of the values obtained.

\section{Results and discussion}

The concentrations of sodium and chloride in the air determined from filter analyses and corrected for the volume of air passed through each filter are shown in Table 2. The height at which the blimp was flown and the date and duration of each flight are also given.

It is probably unwise to draw any conclusions from the data for flights $3,5,6$, and 7 , because the concentrations are close to the detection limit. However, for the majority of the remaining flights there is a difference in the concentration of sea-salt ions of a factor of 2 or more between the ground and the blimp. The differences are not consistent: flights 1, 4, and 9 show increased salt aloft, whereas in flights 2 and 8 there is more salt near ground level.

The ratio of sodium to chloride in each filter is also given in Table 2. In the samples well above the detection limit, the ratios are in most cases slightly above the seawater ratio of 0.557 (Pytkowicz and Kester 1971). It is known that chloride may be lost from aged seasalt aerosol (Pio and Lopes 1998), and deviations from the seawater ratio may therefore give an indication of the age of the aerosol. However, given the uncertainties in the measurements, the small deviations seen in the dataset presented are not sufficient for drawing robust conclusions.

\section{a. Case study_Flight 9}

On the final run, a small meteorological sonde measuring temperature, pressure, wind speed, and wind direction was placed on the blimp to take profiles of the prevailing meteorological conditions just prior to the airsampling pump being sent aloft to collect an aerosol sample. Plots of wind speed, wind direction, and temperature measured by the sonde up to 300-m altitude are shown in Fig. 4 (the two traces are for the ascent and descent of the blimp). As soon as the blimp was back at the surface, the meteorological sonde was replaced with the air-sampling pump. The blimp was then deployed again at $150 \mathrm{~m}$, and the pump was run for $7 \mathrm{~h}$.

At a height of around $30 \mathrm{~m}$, there is a clear switch in the wind direction from northeast to southwest. This could also be observed visually as the blimp ascended. The temperature profile shows an inversion, with the temperature at $150 \mathrm{~m}$ (where the blimp was flown) being around $5^{\circ} \mathrm{C}$ warmer than at ground level. On this occasion, very marked differences were found between the aerosol collected at ground level and that collected on the unit on the blimp, with the air aloft containing large amounts of sea salt. 
TABLE 2. Concentrations of aerosol chloride $(\mathrm{Cl})$ and sodium $(\mathrm{Na})$ in the air $\left(\mathrm{ng} \mathrm{m}^{-3}\right)$ derived from filter analyses.

\begin{tabular}{|c|c|c|c|c|c|c|c|c|c|c|c|}
\hline \multirow[b]{2}{*}{ Flight } & \multicolumn{2}{|c|}{$\mathrm{Cl}$} & \multicolumn{2}{|c|}{$\mathrm{Na}$} & \multirow{2}{*}{$\begin{array}{l}\text { Height of } \\
\text { blimp (m) }\end{array}$} & \multicolumn{2}{|c|}{$\mathrm{Na}: \mathrm{Cl}$ ratio } & \multirow{2}{*}{$\begin{array}{c}\text { Flight date } \\
\text { (2000) }\end{array}$} & \multirow{2}{*}{$\begin{array}{l}\text { Flight } \\
\text { duration } \\
\text { (h) }\end{array}$} & \multirow[b]{2}{*}{ Comments } & \multirow{2}{*}{$\begin{array}{c}\text { Surface wind } \\
\text { speed }\left(\mathrm{m} \mathrm{s}^{-1}\right) / \\
\text { direction }\end{array}$} \\
\hline & $0.1 \mathrm{~m}$ & Blimp & $0.1 \mathrm{~m}$ & Blimp & & $0.1 \mathrm{~m}$ & Blimp & & & & \\
\hline 1 & 840 & -* & 581 & 1209 & 200 & 0.69 & -* & 9 Jan & 3.5 & More sea salt aloft & $7.0 / 230^{\circ}$ \\
\hline 2 & 421 & 234 & 303 & 154 & 250 & 0.72 & 0.66 & $10 \mathrm{Jan}$ & 4.0 & Less sea salt aloft & $0.0 / 0^{\circ}$ \\
\hline 3 & 4 & 4 & 3 & 6 & 100 & 0.75 & 1.50 & $11 \mathrm{Jan}$ & 3.0 & Close to detection limit & $2.0 / 050^{\circ}$ \\
\hline 4 & 18 & —* & 14 & 186 & 200 & 0.78 & —* & $13 \mathrm{Jan}$ & 3.5 & More sea salt aloft & $3.0 / 070^{\circ}$ \\
\hline 5 & 5 & 7 & 17 & 10 & 200 & 3.40 & 1.43 & 19 Jan & 3.5 & Close to detection limit & $0.5 / 130^{\circ}$ \\
\hline 6 & 8 & 5 & 16 & 18 & 300 & 2.00 & 3.60 & 29 Jan & 3.5 & Close to detection limit & $2.0 / 210^{\circ}$ \\
\hline 7 & 9 & 36 & 6 & 20 & 70 & 0.67 & 0.56 & 6 Feb & 4.0 & Close to detection limit & $6.5 / 060^{\circ}$ \\
\hline 8 & 114 & 70 & 95 & 49 & 250 & 0.83 & 0.70 & 7 Feb & $7.5^{* *}$ & Less sea salt aloft & $3.0 / 180^{\circ}$ \\
\hline \multirow[t]{6}{*}{9} & 92 & 3735 & 111 & 2384 & 150 & 1.21 & 0.64 & $10 \mathrm{Feb}$ & $7.0 * *$ & More sea salt aloft & $3.0 / 100^{\circ}$ \\
\hline & 99 & & 66 & & & 0.67 & & & & & \\
\hline & 70 & & 116 & & & 1.66 & & & & & \\
\hline & 81 & & 65 & & & 0.80 & & & & & \\
\hline & 85 & & 55 & & & 0.65 & & & & & \\
\hline & 63 & & 54 & & & 0.86 & & & & & \\
\hline 9 Mean & 82 & & 78 & & & 0.95 & & & & & \\
\hline 9 std dev & 13 & & 28 & & & & & & & & \\
\hline
\end{tabular}

* No $\mathrm{Cl}$ value derived because of problems with the ion chromatograph.

** Blimp brought down halfway through flight and batteries replaced to extend flight time.

The wind at $150 \mathrm{~m}$ comes from a direction of around $215^{\circ}$. It had therefore recently passed over the coast only a few kilometers to the west of Halley, where open water is present much of the summer. The wind at ground level, however, arrives from around $55^{\circ}$ across the Brunt Ice Shelf and may have covered a long distance since passing over open water. The concentrations of sea salt in the two air masses are therefore consistent with their recent histories.

During this flight, a number of pumps were run simultaneously at ground level to check that the sampling procedure was consistent. The mean and standard deviation of the concentrations of sodium and chloride in these samples are given in Table 2. Although two of the sodium analyses are somewhat high for unknown reasons, the variability is very much less than that between the ground and the blimp. We can therefore be confident that the differences between the aerosol at ground level and that aloft for this run are real.

\section{Conclusions}

A helium blimp was used to hoist a lightweight, inexpensive sampling system aloft to collect aerosol on filters from heights of a few hundred meters above the ground. Initial studies show that at times air masses above the Brunt Ice Shelf in the Antarctic have very different aerosol composition to those sampled at
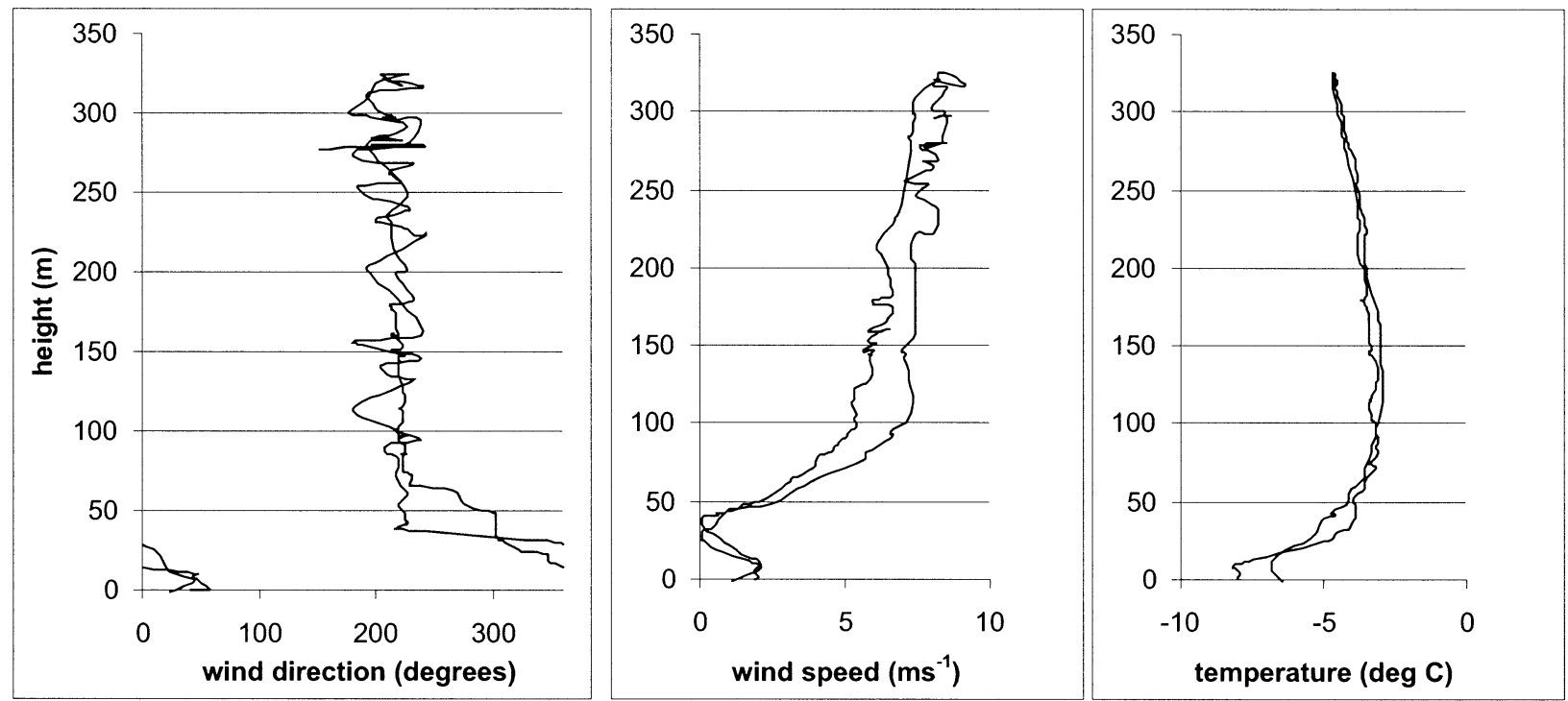

Fig. 4. Profiles of wind direction, wind speed, and temperature above Halley on 10 Feb 2001. 
ground level. In the one case investigated in more detail, this was coincident with strong stratification of the lower atmosphere.

The finding that aerosol is not well mixed through the troposphere has implications for the study of aerosol recorded in ice cores. Falling snow picks up aerosol throughout the air column it passes through, and so samples of aerosol collected at ground level-regularly taken at many Antarctic stations-may not be representative of what is ultimately trapped in the ice.

Acknowledgments. We thank the meteorologists and other station staff at Halley for their assistance in performing the experiments with the blimp. Russ Ladkin kindly allowed us to use data from the RuSonde profiling sonde, and both he and Stephane Bauguitte gave helpful comments and suggestions on the manuscript.

\section{REFERENCES}

Argentini, S., G. Mastrantonio, and A. Viola, 1999: Estimation of turbulent heat fluxes and exchange coefficients for heat at Dumont d'Urville, East Antarctica. Antarct. Sci., 11, 93-99.

Artaxo, P., E. T. Fernandes, J. V. Martins, M. A. Yamasoe, P. V. Hobbs, W. Maenhaut, K. M. Longo, and A. Castanho, 1998: Large-scale aerosol source apportionment in Amazonia. J. Geophys. Res., 103, $31837-31847$.

_ R. C. de Campos, E. T. Fernandes, J. V. Martins, Z. F. Xiao, O. Lindqvist, M. T. Fernandez-Jimenez, and W. Maenhaut, 2000 Large scale mercury and trace element measurements in the Amazon basin. Atmos. Environ., 34, 4085-4096.

Beck, F., and P. Ruetschi, 2000: Rechargeable batteries with aqueous electrolytes. Electrochim. Acta, 45, 2467-2482.

Bergin, M. H., E. A. Meyerson, J. E. Dibb, and P. A. Mayewski, 1998: Relationship between continuous aerosol measurements and firn core chemistry over a 10-year period at the South Pole. Geophys. Res. Lett., 25, 1189-1192.

Eaton, F. D., B. B. Balsley, R. G. Frehlich, R. J. Hugo, M. L. Jensen, and K. A. McCrae, 2000: Turbulence observations over a desert basin using a kite/tethered-blimp platform. Opt. Eng., 39, 2517 2526.

Greenberg, J. P., A. Guenther, P. Zimmerman, W. Baugh, C. Geron, K. Davis, D. Helmig, and L. F. Klinger, 1999: Tethered balloon measurements of biogenic VOCs in the atmospheric boundary layer. Atmos. Environ., 33, 855-867.

Hall, J. S., 1998: Aerosol chemistry and air-snow transfer in coastal Antarctica. Ph.D. thesis, Open University, 290 pp.

Harder, S., S. G. Warren, and R. J. Charlson, 2000: Sulfate in air and snow at the South Pole: Implications for transport and deposition at sites with low snow accumulation. J. Geophys. Res., 105, 22 825-22 832.

Helmig, D., and Coauthors, 1998: Vertical profiling and determination of landscape fluxes of biogenic nonmethane hydrocarbons within the planetary boundary layer in the Peruvian Amazon. J. Geophys. Res., 103, 25 519-25 532.

Hogan, A. W., and A. J. Gow, 1993: Particle-transport to the snow surface at the South-Pole-The beginning of a tropospheric history. Tellus, 45B, 188-207.

King, J. C., 1989: Low-level wind profiles at an Antarctic coastal station. Antarct. Sci., 1, 169-178.

Knapp, K. G., M. L. Jensen, B. B. Balsley, J. A. Bognar, S. J. Oltmans, T. W. Smith, and J. W. Birks, 1998: Vertical profiling using a complementary kite and tethered balloon platform at
Ferryland Downs, Newfoundland, Canada: Observation of a dry, ozone-rich plume in the free troposphere. J. Geophys. Res., 103, 13 389-13 397

König-Langlo, G., J. C. King, and P. Pettre, 1998: Climatology of the three coastal Antarctic stations Dumont d'Urville, Neumayer, and Halley. J. Geophys. Res. 103, $10935-10946$.

Kuck, L. R., and Coauthors, 2000: Measurements of landscape-scale fluxes of carbon dioxide in the Peruvian Amazon by vertical profiling through the atmospheric boundary layer. J. Geophys. Res., 105, 22 137-22 146.

Mazzera, D. M., D. H. Lowenthal, J. C. Chow, J. G. Watson, and V. Grubisic, 2001: PM10 measurements at McMurdo Station, Antarctica. Atmos. Environ., 35, 1891-1902.

Mellor, M., and U. Radok, 1960: Some properties of drifting snow. Antarctic Meteorology, L. J. Dwyer, Ed., Pergamon Press, 333 346.

Minikin, A., M. Legrand, J. Hall, D. Wagenbach, C. Kleefeld, E. Wolff, E. C. Pasteur, and F. Ducroz, 1998: Sulfur-containing species (sulfate and methanesulfonate) in coastal Antarctic aerosol and precipitation. J. Geophys. Res., 103, 10 975-10 990.

Paul, S. K., 2000: A study of chloride aerosol, total aerosol and ice nuclei in the Indian regions. Pure Appl. Geophys., 157, 15411556.

Pio, C. A., and D. A. Lopes, 1998: Chlorine loss from marine aerosol in a coastal atmosphere. J. Geophys. Res., 103, 25 263-25 272.

Pisano, J. T., J. W. Drummond, and D. R. Hastie, 1996: A lightweight $\mathrm{NO}_{2}$ instrument for vertical height profiles. J. Atmos. Oceanic Technol., 13, 400-406.

Pomeroy, J. W., and H. G. Jones, 1996: Wind-blown snow: Sublimation, transport and changes to polar snow. Chemical Transport between the Atmosphere and Polar Snow, E. W. Wolff and R. C. Bales, Eds., Springer-Verlag, 453-489.

Pytkowicz, R. M., and D. R. Kester, 1971: The physical chemistry of seawater. Oceanography and Marine Biology: Annual Reviews, H. Barnes, Ed., George Allen and Unwin, 11-60.

Rankin, A. M., and E. W. Wolff, 2000: Ammonium and potassium in snow around an emperor penguin colony. Antarct. Sci., 12, 154-159.

- — - and V. Auld, 2000: Frost flowers as a source of fractionated sea salt aerosol in the polar regions. Geophys. Res. Lett., 27, 3469-3472.

Rojas, C. M., R. E. Vangrieken, and W. Maenhaut, 1993: Elemental composition of aircraft-sampled aerosols above the southern bight of the North-Sea. Water Air Soil Pollut., 71, 391-404.

Sanhueza, E., E. Fernandez, L. Donoso, and J. Romero, 2000: Boundary layer ozone in the tropical America Northern Hemisphere region. J. Atmos. Chem., 35, 249-272.

Sheridan, P. J., R. C. Schnell, W. H. Zoller, N. D. Carlson, R. A. Rasmussen, J. M. Harris, and H. Sievering, 1993: Composition of $\mathrm{Br}$-containing aerosols and cases related to boundary-layer ozone destruction in the Arctic. Atmos. Environ., 27, 2839-2849.

Vincent, J. H., 1989: Aerosol Sampling-Science and Practice. John Wiley and Sons, $390 \mathrm{pp}$.

Wagenbach, D., F. Ducroz, R. Mulvaney, L. Keck, A. Minikin, M. Legrand, J. S. Hall, and E. W. Wolff, 1998: Seasalt aerosol in coastal Antarctic regions. J. Geophys. Res., 103, $10961-10974$.

Wolff, E. W., 1996: The record of aerosol deposited species in ice cores, and problems of interpretation. Chemical Exchange between the Atmosphere and Polar Snow, E. W. Wolff and R. C. Bales, Eds., Springer-Verlag, 1-19.

- J. S. Hall, R. Mulvaney, E. C. Pasteur, D. Wagenbach, and M. Legrand, 1998a: Relationship between the chemistry of air, fresh snow and firn cores for aerosol species in coastal Antarctica. $J$. Geophys. Res., 103, $11057-11070$.

- M. R. Legrand, and D. Wagenbach, 1998b: Coastal Antarctic aerosol and snowfall chemistry. J. Geophys. Res., 103, $10927-$ 10934 